\title{
HPV-16 E7 TCR Expressing T-cells
}

National Cancer Institute

\section{Source}

National Cancer Institute. HPV-16 E7 T CR Expressing T-cells. NCI Thesaurus. Code C128485.

A preparation of allogeneic, genetically eng ineered $\mathrm{T}$-lymphocytes transduced with a retroviral vector MSGV1 that encodes a T-cell receptor (TCR) targeting a specific epitope of the human papillomavirus (HPV) type 16 oncoprotein E7 (HPV-16 E7 TCR), with potential antineoplastic activity. The TCR especially recognizes and binds with high affinity to the HPV 16 E7 11-19 epitope. Upon administration, HPV-16 E7 expressing T-cells target and bind to tumor cells expressing the HPV-16 E7 antigen leading to selective cytotoxicity in HLA-A2-positive, HPV-16 E7-expressing tumor cells. HPV16 E7, a tumorassociated antigen (TAA), overexpressed in a variety of tumor cell types while not expressed in normal, healthy cells, plays a key role in tumor cell proliferation. E7 11-19 is a naturally processed epitope of HPV-16 E7 that binds specifically to human leukocyte antigen (HLA)-A*02:01 and that has been isolated from the surface of HPV-16 positive, HLA-A*02:01-positive tumor cells. 